\title{
Raman mapping of coesite inclusions in garnet from the Kokchetav Massif (Northern Kazakhstan)
}

\author{
Andrey V. Korsakov ${ }^{\mathrm{a}, *}$, Didier Hutsebaut ${ }^{\mathrm{b}}$, Karel Theunissen ${ }^{\mathrm{c}}$, \\ Peter Vandenabeele ${ }^{\mathrm{b}}$, Alexander S. Stepanov ${ }^{\mathrm{a}}$ \\ ${ }^{a}$ Institute of Geology and Mineralogy of Siberian Branch Russian Academy of Sciences, Koptyug Pr. 3, Novosibirsk 630090, Russia \\ ${ }^{\mathrm{b}}$ Ghent University, Department of Analytical Chemistry Raman Research Group, Proeftuinstraat 86, B-9000 Ghent, Belgium \\ ${ }^{\mathrm{c}}$ Department of Geology and Mineralogy, Royal Museum for Central Africa, B-3080 Tervuren, Belgium
}

Received 2 November 2006; received in revised form 31 March 2007; accepted 2 April 2007

\begin{abstract}
Coesite inclusions occur in a wide range of lithologies and coesite is therefore a powerful ultrahigh-pressure (UHP) indicator. The transformation of coesite to quartz is evidenced by three optically well identifiable characteristics (e.g. palisade textures, radial crack patterns, polycrystalline quartz pseudomorphs). Under overpressure monomineralic coesite (on an optical basis), lacking the above transformation characteristics may survive. Raman micro-spectroscopy was applied on monomineralic coesite inclusions in garnet porphyroblasts from diamond-bearing garnet-clinozoisite-biotite gneisses of the Barchi-Kol area (Kokchetav Massif, Northern Kazakhstan). These coesite inclusions are euhedral and display a characteristic anisotropic hallo. However, Raman maps and separate spectra of these inclusions display shifted bands for coesite and quartz. Microscopically undetectable, quartz shows on the Raman map as a thin shell around coesite inclusion. Shift of the main coesite band allows to estimate their overpressure: coesite inclusions record 0-2.4 GPa in garnet and zircon. The quartz shell remains under lower pressure 0-1.6 GPa. The possible application of coesite and quartz Raman geobarometers for UHP metamorphic rocks is discussed.
\end{abstract}

(C) 2007 Elsevier B.V. All rights reserved.

Keywords: Coesite; Raman spectroscopy; Raman mapping; Raman geobarometer; UHP metamorphism; Kokchetav Massif

\section{Introduction}

The identification of relics of UHP metamorphism is a big challenge, since these rocks frequently undergo a multi-phase metamorphism hiding any sign of the UHP stage. Since 1984, coesite has been known to be the best indicator of UHP metamorphism [1,2]. Coesite is common in a wide spectrum of lithologies and its former presence is optically easily recognizable by three characteristics associated with its transformation to quartz: (a) palisade quartz textures, (b) polycrystalline quartz pseudomorphs and (c) radial crack patterns around quartz inclusions. Unfortunately, although very helpful, these features only apply on rocks with relatively low exhumation rates, where the transformation of coesite to quartz is significant. Because of the sluggish reaction kinetics of the coesite to quartz transformation, fast cooling and high exhumation rates will promote

\footnotetext{
* Corresponding author. Tel.: +7 38333325 17; fax: +7 3833332792 .

E-mail address: korsakov@uiggm.nsc.ru (A.V. Korsakov).
}

the preservation of monomineralic coesite inclusions $[3,4]$. The recent discovery of single coesite inclusions, without any trace of radial cracks, preserving significant overpressure [5-7], highlights the importance of Raman spectroscopy as a very powerful tool in UHP research.

In a series of diamond-anvil cell experiments to $40 \mathrm{GPa}$, demonstrated that the room temperature Raman spectra of coesite and $\alpha$-quartz show a clear pressure-dependent shift, and individual bands show a clear pressure-dependent shift with the coesite bands at 116,176 , and $521 \mathrm{~cm}^{-1}$ and the quartz bands at $464 \mathrm{~cm}^{-1}$ being more sensitive than other bands to the change in pressure [8]. Moreover, changes in frequency and linewidth of the 206 and $464 \mathrm{~cm}^{-1} \mathrm{~A} 1$ Raman modes of quartz have been recently proposed to be used as a pressure sensor [9]. The most intense coesite band at $521 \mathrm{~cm}^{-1}$ (at ambient pressure) has a strong, characteristic pressure shift of $2.9 \pm 0.1 \mathrm{~cm}^{-1} / \mathrm{GPa}$ [8], while the most intense band of quartz at $464 \mathrm{~cm}^{-1}$ (at ambient pressure) is used for pressure measurements in the present study (characteristic pressure shift of $9 \pm 0.5 \mathrm{~cm}^{-1} / \mathrm{GPa}$ [9]). Applying these geobarometers for "monomineralic" coesite 

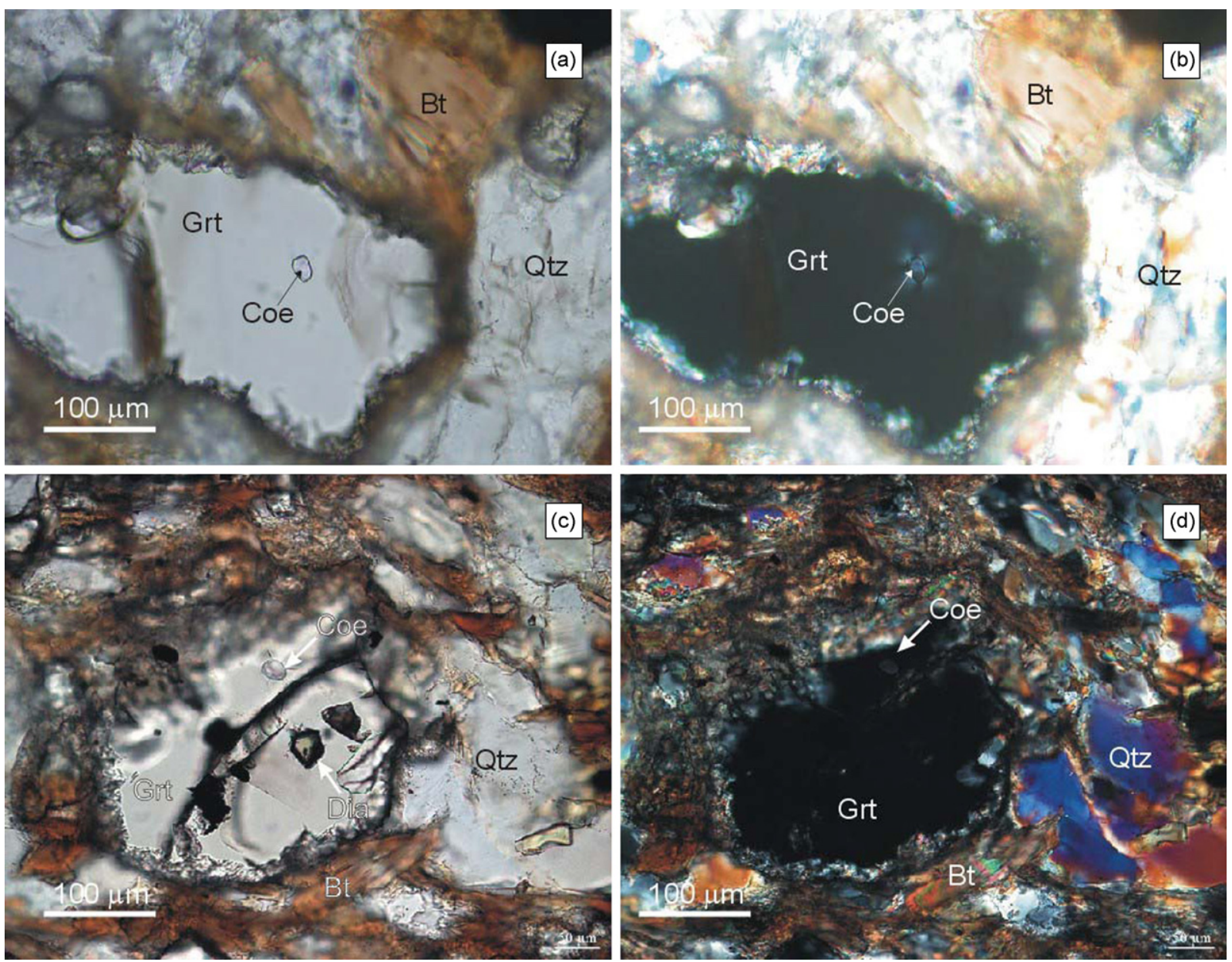

Fig. 1. Photomicrograph of "monomineralic" coesite inclusions in garnet (sample B92-331a). (a and b) Unexposed coesite inclusion with hallo in garnet (plan and polarized nicols). (c and d) Coesite inclusion in garnet, exposed on the surface (plan and polarized nicols, respectively).

inclusions (following the definition of Parkinson [6]) in refractory minerals such as diamond, garnet, zircons and kyanite from different ultrahigh-pressure metamorphic (UHPM) complexes [5,6,10] and some kimberlitic diamonds [7] reveals several particular features, which can be summarized as follow. Raman spectra of all "monomineralic" coesite inclusions contain main quartz band $\left(464 \mathrm{~cm}^{-1}\right.$ at ambient pressure) located at $464-477 \mathrm{~cm}^{-1}$, indicating that in addition to coesite optically undetectable quartz is present within the inclusions. The maximum Raman shift of the main coesite band $\left(521 \mathrm{~cm}^{-1}\right.$ at ambient pressure) does not exceed $524 \mathrm{~cm}^{-1}$ for inclusions in kyanite, $526 \mathrm{~cm}^{-1}$ for inclusions in garnet and zircon, while in kimberlitic diamonds is the main coesite band appears at about $532 \mathrm{~cm}^{-1}$ [7]. Both coesite and quartz remain under high pressure as reflected on the shift of their Raman bands. The pressure was determined from the upshift of the dominant coesite and quartz band according to $P(\mathrm{GPa})=(\nu-521) / 2.9$ [8] and $P(\mathrm{GPa})=(v-464) / 9$ [9], respectively, and $v$ is the frequency value for the shifted Raman band. Differences in pressure value for quartz $(\leq 1.5 \mathrm{GPa})$ and coesite $(\leq 2.4 \mathrm{GPa})$ within the same inclusions contradict the elastic models proposed by Zhang [11]. Ye et al. [10] overpressures of up to $2.4 \mathrm{GPa}$ as documented for coesite inclusions in zircon, are related to the extent of coesite to quartz transition. Our results do not support their conclusions.

This work was initiated to clarify the distribution of optically undetectable quartz within the "monomineralic" coesite inclusions in garnet, and to confirm the inferred occurrence of coesite (identified only by optical microscopy) as small crystals included in garnet from diamondiferous rocks of the Kokchetav Massif (Fig. 1).

\section{Experimental techniques}

Raman spectra were obtained using a Kaiser System Hololab 5000R modular Raman microspectrometer (f/1.8) (KOSI, Ecully, France). The microscope was fitted with a $100 \times$ objective (PL Fluotar L, N.A. 0.75, W.D. $4.7 \mathrm{~mm}$, Leica). Samples were excited using $45-50 \mathrm{~mW}$ of $785 \mathrm{~nm}$ laser light from a diode laser (Toptica Photonics AG, Martinsried/Munich, Germany). The scattered light is guided to the spectrograph by means of a confocal, $15 \mu \mathrm{m}$ aperture collection fiber. A back illuminated deep depletion Pelletier cooled CCD detector (Andor, Belfast, Northern Ireland) operating at $-70^{\circ} \mathrm{C}$ was used for the detection of the scattered light. The Raman signal was collected in the spectral interval of $100-3100 \mathrm{~cm}^{-1}$ with a 

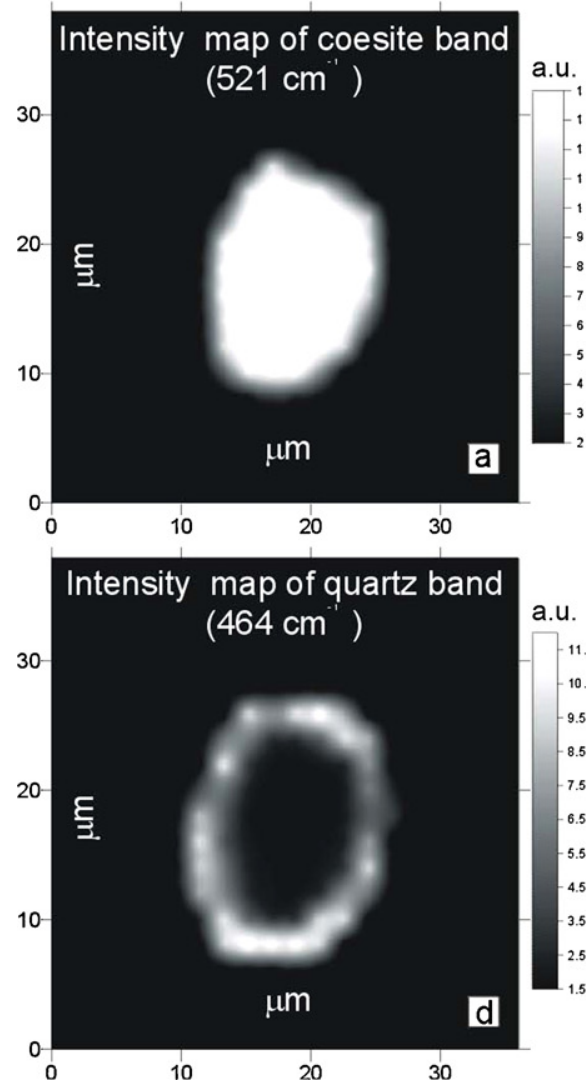

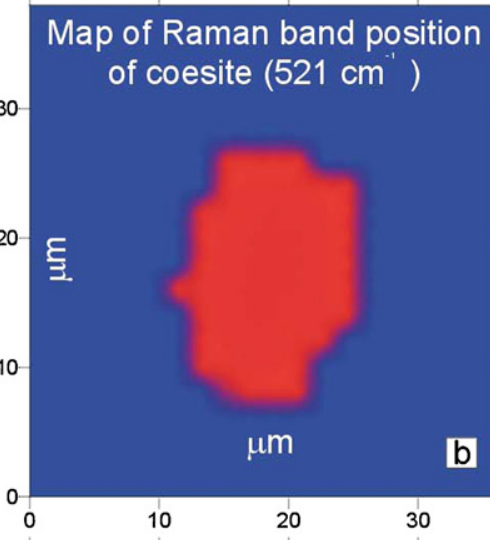

Map of Raman band position of quartz $\left(464 \mathrm{~cm}^{-1}\right)$

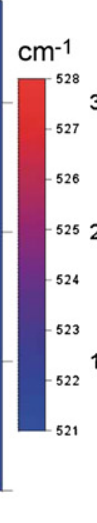

\section{Residual pressure for coesite} inclusion, Gpa

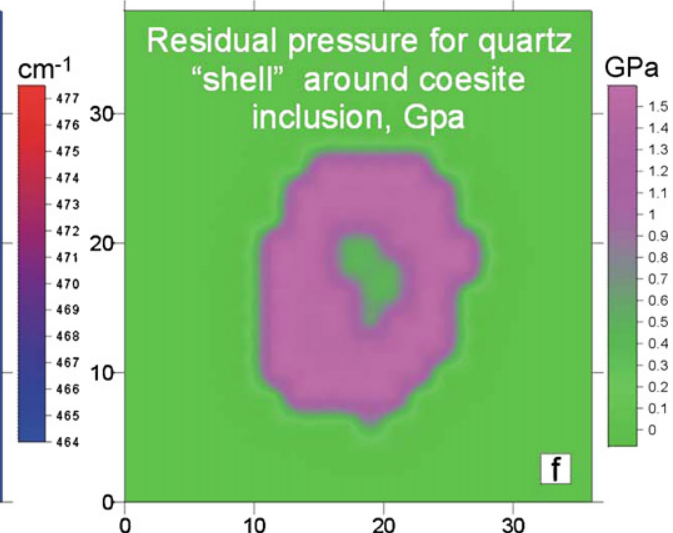

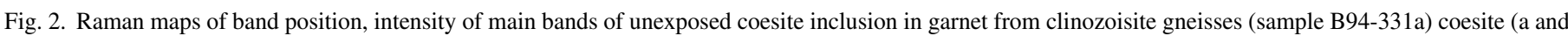

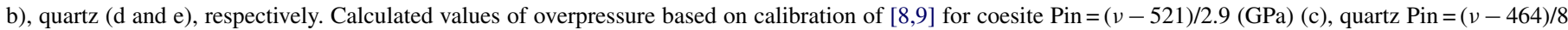
(GPa) (f).

spectral resolution of $4 \mathrm{~cm}^{-1}$. Further details of the calibration procedure can be found elsewhere [12]. Two $20 \times 20$ mappings were performed with a spacing of 1.44 and $1.82 \mu \mathrm{m}$ for exposed and unexposed coesite inclusions in garnet, respectively. The spectra were recorded with $15 \mathrm{~s}$ accumulation time.

Coesite and $\alpha$-quartz are distinguishable by their diagnostic Raman spectra. Coesite is characterized by a strong band at $521 \mathrm{~cm}^{-1}$, along with other weaker bands at $116,151,176$, 204, 269, 326, 355, 427, 466, 661, 795, 815, 1036, 1065, $1144,1164 \mathrm{~cm}^{-1}$ at room temperature and atmospheric pressure $[8,13,14]$. The main band of $\alpha$-quartz is located at $464 \mathrm{~cm}^{-1}$ with subsidiary bands at 128, 206, 265, 355, 394, 401, 450, 511, 696, $796,808,1069,1085,1162$ and $1230 \mathrm{~cm}^{-1}$ [8]. However, only bands marked in italic fonts were documented in this study. Hostgarnet is characterised by a strong band at $905 \mathrm{~cm}^{-1}$, along with other weaker bands at 180, 231, 366, 485, 508, 557, 638, 845 and $1036 \mathrm{~cm}^{-1}$.

\section{Geological background and sample description}

The Kokchetav Massif (Northern Kazakhstan) represents a slice of continental crust that was subducted to at least $120 \mathrm{~km}$ depth, within the diamond stability field [15-17]. The peak metamorphic temperature is constrained at $950-1000^{\circ} \mathrm{C}$ [17-20]. A minimum pressure of $4.3 \mathrm{GPa}$ is given by the presence of diamond and the maximum pressure of about 6.0 GPa is defined by the stability of dolomite [21,22]. A summary of the geology, tectonic setting and geochronological data for this region has been provided by $[17,18,20,23-26]$. The diamondiferous rocks are present in the UHP unit I of the Zerenda Series. This unit consists mainly of garnet-biotite gneisses and schists with alternating marbles, calc-silicate rocks and eclogites [17]. We investigate coesite inclusions in zircon and garnet from diamondiferous clinozoisite gneisses, collected at the Barchi-Kol localities [27-29]. Garnet in these gneisses displays a large unzoned core and narrow rims with decreasing $\mathrm{Ca}$ and increasing $\mathrm{Mg}$ contents [28,29]. Similar zoning has been observed in some dolomitic metacarbonates [20]. It was suggested that the observed garnet zoning reflects decompression [20] from UHP to granulite-facies conditions. Additional information on other rocks types can be found elsewhere [27,30-34].

Monomineral coesite inclusions are widespread in the diamond-bearing rocks of the Barchi-Kol area (Kokchetav Massif, Northern Kazakhstan). Garnets from zoisite gneisses [28] frequently contain euhedral inclusions with low color of interference and display a strong anisotropic hallo around these inclusions (Fig. 1). Occasionally, the inclusions are surrounded by extremely tiny cracks, indicating that they could be coesite. Over 50 monomineral coesite inclusions were identified within 

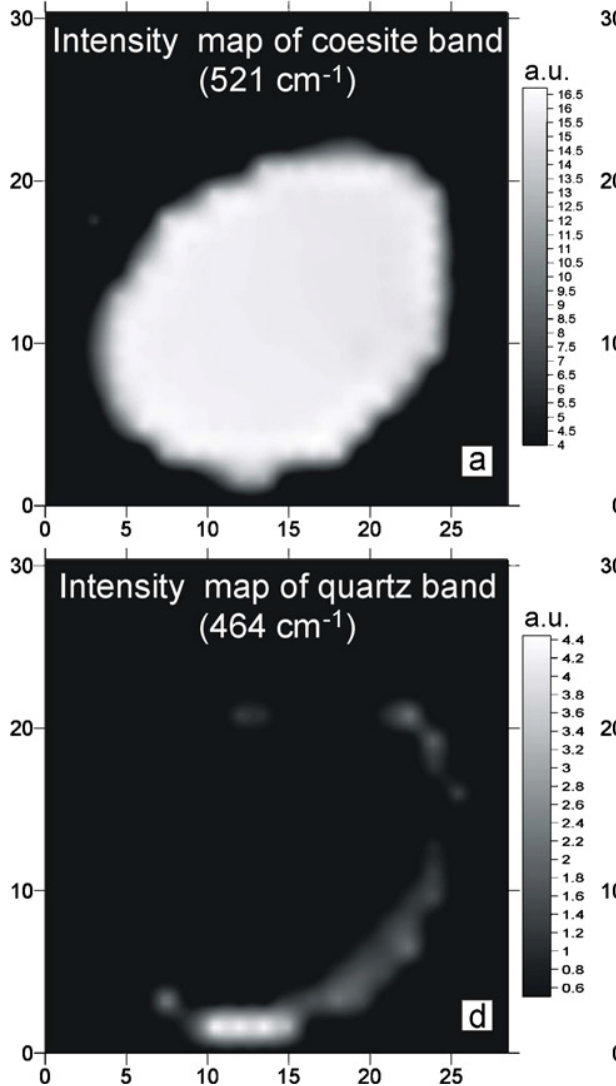
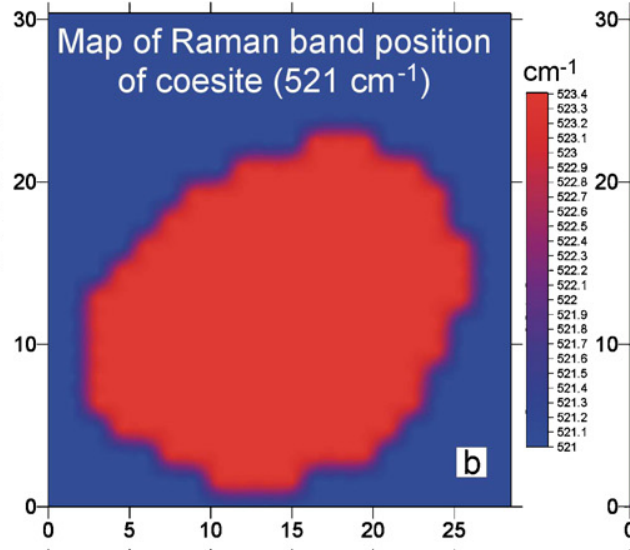

30

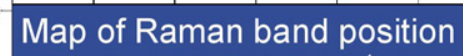
of quartz $\left(464 \mathrm{~cm}^{-1}\right)$

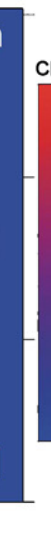

30 Residual pressure for coesite inclusion, Gpa

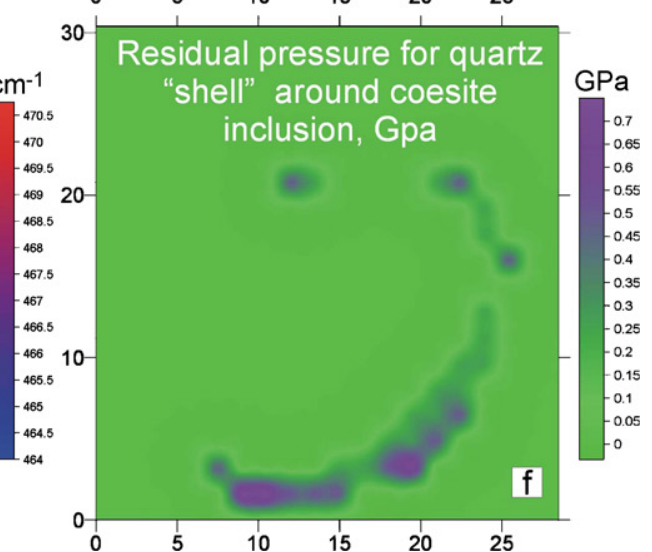

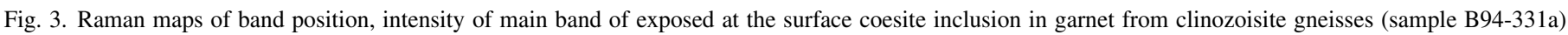

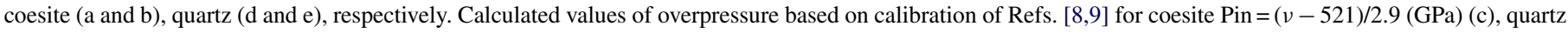
$\operatorname{Pin}=(v-464) / 8(\mathrm{GPa})(\mathrm{f})$.

the single thin section. They are often coexist with diamond (Fig. 1c).

\subsection{Euhedral coesite inclusions: exposed and unexposed}

Two coesite (exposed and unexposed Fig. 1a and c, respectively) inclusions were chosen for detailed study. Their Raman maps are presented in Figs. 2 and 3. Contrary to the results of Ye et al. [10], both inclusions characterized by Raman shift of main coesite band $\left(521 \mathrm{~cm}^{-1}\right)$. The highest value of the Raman shift of the unexposed coesite inclusion was documented at $526 \mathrm{~cm}^{-1}$ (Fig. 2 and Table 1), whereas that of the exposed one at $523 \mathrm{~cm}^{-1}$. This fact indicates that the pressure only partly released during polishing and surprisingly even the exposed coesite inclusion remains under high pressure $(0.5 \mathrm{GPa}$ using calibration of Hemley [8]). Both exposed and unexposed coesite inclusions have a homogeneous core and changes in their peak positions and intensity occur within the very thin rim zone 1-2 $\mu \mathrm{m}$ (Figs. 2 and 3).

Contrary to the observations of Ye et al. [10] in our study: (1) the quartz bands are always present in the analysed coesite inclusions; (2) there is a weak relation between the Raman shift of coesite and coexistent quartz bands; (3) the intensity of the quartz bands is independent on the Raman shift of the main coesite band; (4) individual coesite and quartz bands show different shifts even within the same inclusion; (5) splitting of the main quartz band $\left(464 \mathrm{~cm}^{-1}\right)$ occurs in some unexposed coesite inclusions.

More detailed information on the distribution of optically undetectable quartz within coesite inclusions was obtained using the Raman mapping technique. Quartz occurs as a thin shell ( $\sim 3 \mu \mathrm{m}$ in thickness) surrounding coesite completely or partly (Figs. 2 and 3, respectively). Two strong bands, located at 477 and $468 \mathrm{~cm}^{-1}$, are characterize almost all unexposed coesite inclusions (Figs. $4 \mathrm{~b}$ and 5). Only the most external part of the coesite inclusions is characterized by a single mode at $477 \mathrm{~cm}^{-1}$ (Fig. 4). Locally, within the most external zone of coesite inclusion in garnet, there are some points where only characteristic bands of quartz were detected (e.g. 134, 235 and 476 corresponding to bands 128, 206 and 464 at ambient pressure, Table 1); therefore, most likely the $477 \mathrm{~cm}^{-1}$ mode is assigned to quartz (Fig. 5), while the $468 \mathrm{~cm}^{-1}$ mode is a bit more difficult to interpret. It is worth-noted that only one mode $\left(470 \mathrm{~cm}^{-1}\right)$ was documented for exposed coesite inclusions (Fig. 4d).

\section{Discussion}

Raman mapping of "monomineralic" coesite inclusions in garnet reveals the following important features. Pressure inside coesite inclusions is uniform and isotropic. This result is in good agreement with the elastic model of Zhang [11]. Quartz nucleated and formed at incluison-host interface. This observa- 
Table 1

Frequencies $\left(\mathrm{cm}^{-1}\right)$ of coesite and quartz Raman bands in spectra of representative unexposed coesite inclusion

\begin{tabular}{|c|c|c|c|c|c|c|c|}
\hline \multicolumn{4}{|l|}{ Coesite } & \multicolumn{4}{|l|}{ Quartz } \\
\hline$v\left(\mathrm{~cm}^{-1}\right)$ & $(\mathrm{d} v / \mathrm{d} P)_{T}\left(\mathrm{~cm}^{-1} / \mathrm{GPa}\right)$ & $v\left(\mathrm{~cm}^{-1}\right)$ & $P(\mathrm{GPa})$ & $v\left(\mathrm{~cm}^{-1}\right)$ & $(\mathrm{d} v / \mathrm{d} P)_{T}\left(\mathrm{~cm}^{-1} / \mathrm{GPa}\right)$ & $v\left(\mathrm{~cm}^{-1}\right)$ & $P(\mathrm{GPa})$ \\
\hline 116 & $7.4 \pm 0.4$ & 131.04 & 2.03 & 128 & $5.5 \pm 0.2$ & 132 & 0.73 \\
\hline 176 & $5.6 \pm 0.2$ & 185.86 & 0.89 & & & & \\
\hline 204 & $2.3 \pm 0.3$ & 208.84 & 1.76 & 206 & $19.9 \pm 0.7$ & 238 & 1.6 \\
\hline 269 & $1.1 \pm 0.2$ & 270.51 & 1.37 & 265 & $3.5 \pm 0.1$ & - & - \\
\hline 427 & $0.45 \pm 0.04$ & 427.22 & 0.49 & & & & \\
\hline 466 & $0.66 \pm 0.06$ & 468.32 & 3.52 & 450 & $4.6 \pm 0.1$ & - & - \\
\hline 521 & $2.9 \pm 0.1$ & 526.2 & 1.93 & 464 & $8.0 \pm 0.2$ & 477 & 1.63 \\
\hline
\end{tabular}

Pressure shifts of the Raman modes of coesite and $\alpha$-quartz after [8].

tion is in a good agreement with recent TEM study of coesite relics from Dora Maira (Italy) [35], which reveals that backtransformation of coesite into quartz starts at grain and twin boundaries. Quartz produced by back-transformation of coesite forms a margin around coesite relics and shows a palisade structure. Moreover quartz has strong preferred orientation, but there is no obvious topotactic relationship between the quartz sub- grains and the adjacent coesite [35]. Therefore, we consider as more likely that the quartz shells are also composed of quartz subgrains with a lattice-preferred orientation.

Raman bands of "monomineralic" coesite inside unfractured garnet show various degrees of shift, indicating different values of overpressure (Table 1). Some coesite inclusions, however, coexist within the same growth zone of host-garnet at a distance
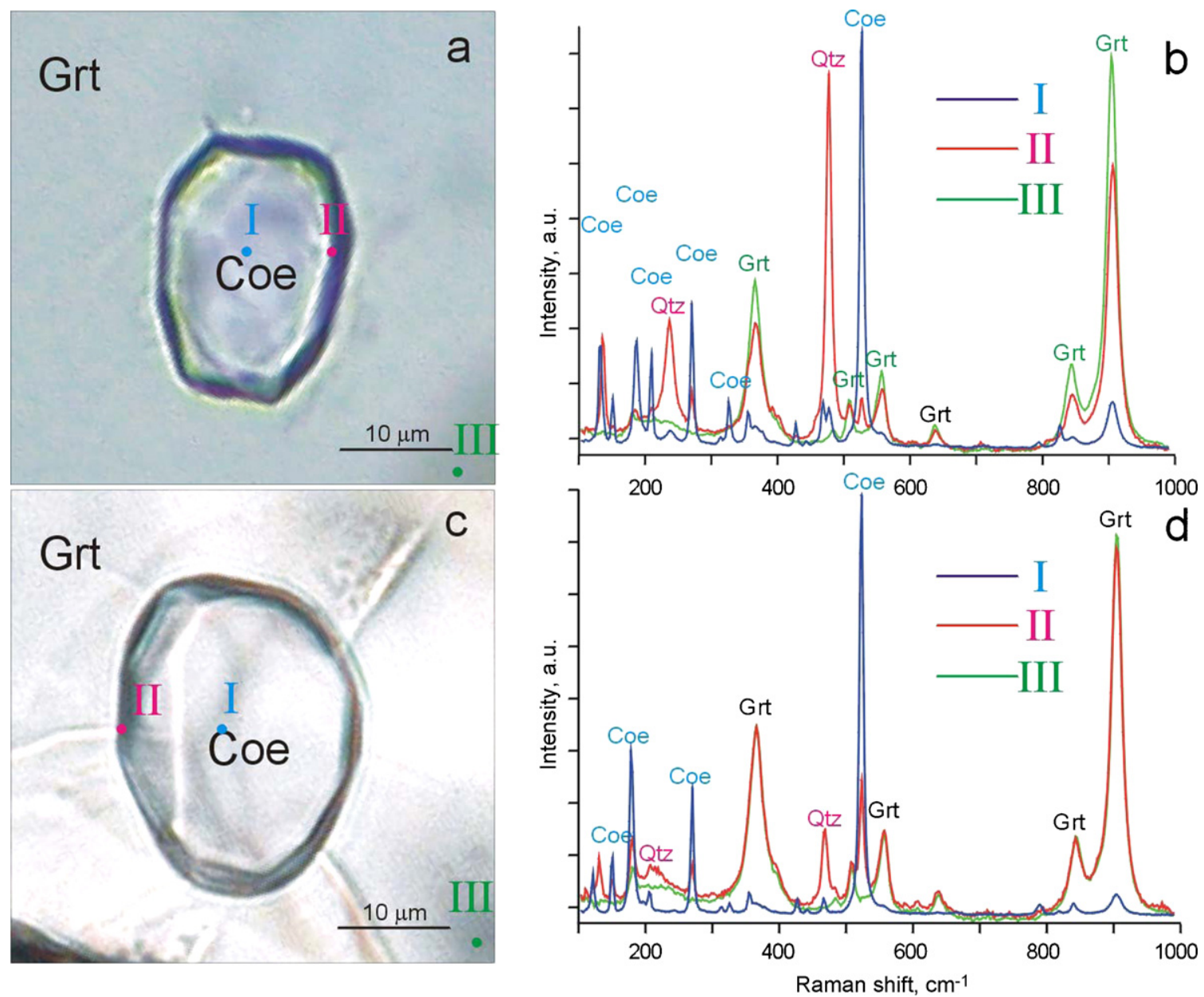

Fig. 4. Photomicrograph of unexposed and exposed (polished) at the surface coesite inclusions chosen for Raman mapping (a-c), respectively. (c and d) Points location. (b-d) Representative Raman spectra of the coesite inclusions and host-garnet: I, blue line for coesite; II, red line for quartz; and III, green line for garnet. 


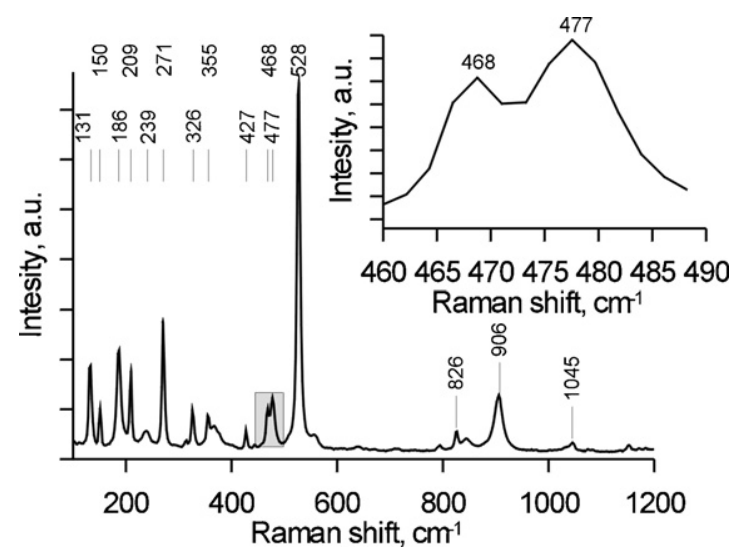

Fig. 5. Representative Raman spectra of unexposed coesite inclusion with splitting mode at $464 \mathrm{~cm}^{-1}$. Shaded area presented on inset with enlargement.

less than $10 \mu \mathrm{m}$. Most likely these coesite inclusions formed at the same $P-T$ conditions and consequently the differences in overpressure could not be explained by the simple elastic model proposed by Zhang [11]. Ye et al. [10] proposed that different values of overpressure related to differences in the extent of coesite to quartz transformation. They found the highest Raman shift of coesite and quartz bands up to $526 \mathrm{~cm}^{-1}$ and up to $470 \mathrm{~cm}^{-1}$, respectively. Their pressure estimates based on calibration of Hemley [8] correspond 2.4 GPa for coesite and 2.0 GPa for quartz. For our samples Raman shift for coesite and quartz bands are comparable with Ref. [10] and only for quartz we found Raman shift up to $477 \mathrm{~cm}^{-1}$. However, using the calibration as Hemley [8], the values of overpressure in our case significantly differ from previous reported results [10] 1.93 and $1.63 \mathrm{GPa}$ for quartz and coesite, respectively. The small difference between the pressure for quartz and coesite (which should be equal and correspond to the equilibrium pressure $2.0 \mathrm{GPa}$ at room temperature), can be related with calibration uncertainties. However in several articles $[5,6,10]$ reported the pressure difference (2.3 GPa for coesite and $1.0 \mathrm{GPa}$ for quartz) is more pronounced and could not be related to uncertainties of calibration. From the one hand, this difference may indicate that coesite and quartz are not in mechanical equilibrium, which would contradict the elastic model of Ref. [11]. On the other hand, quartz shell is likely to be composed of quartz subgrains with a lattice-preferred orientation. The preferred orientation may affect the Raman shift and the calibration of $[8,9]$ can hardly be applied for pressure estimates. The effect of uniaxial stress on Raman spectra of single crystal of $\alpha$-quartz was studied by Tekippe et al. [36]. They found that Raman shift of most intense quartz band at 1081 and $464 \mathrm{~cm}^{-1}$ is about 1.5 and $3.7 \mathrm{~cm}^{-1} / \mathrm{GPa}$. Pressure estimates for quartz, using their calibration are 3-3.6 GPa, significantly higher than the equilibrium pressure of $P_{\text {eq }}=2.0-2.2 \mathrm{GPa}$ [37]. In our case quartz occurs as polycrystalline aggregates with lattice-preferred orientation and Raman shift of such quartz should be about $5-6 \mathrm{~cm}^{-1} / \mathrm{GPa}$ to satisfy equilibrium conditions at room temperature. New experiments on Raman shift for polycrystalline quartz aggregates are required for a better understanding of the coesite to quartz transformation.
The presence of main quartz band $\left(464 \mathrm{~cm}^{-1}\right)$ in large coesite inclusions, with optically undetectable quartz, was first documented by Boyer et al. [14]. In the case of the large coesite crystals which was found in xenoliths from kimberlite pipe Roberts Victor (South Africa) and Grytting eclogite of Norway, it is highly unlikely that an invisible layer of quartz exists above or below the coesite surface. Boyer et al. [14] concluded that there are discrete quartz crystallites (domains or veinlets with the quartz structure in the sub-micron size range) within the lattice of the natural coesites. Our observation and results confirm that sub-micron quartz is present as a shell around coesite inclusions, tracing the initial stage of coesite to quartz transformation. This fact should be taken into account during the modeling of retrogression of coesite into quartz and geodynamical modeling.

\subsection{Coesite-quartz transformation in inclusions and some consequence for UHPM research}

Selective preservation of coesite in inclusions was explained by the high hydrostatic pressure developed in the inclusion, due to the different elastic moduli and thermal expansion coefficients of coesite and garnet as well as due to the volume increase accompanying the transformation of coesite into quartz [10,38,39].

In nature, coesite inclusions occur in various minerals as garnet, pyroxene, kyanite, titanite, zircon, rutile and diamond, which differ in their structures and elastic properties. In particular, the bulk modulus $\left(K_{0}\right)$ ranges from $129 \mathrm{GPa}$ for omphacite to $150 \mathrm{GPa}$ for pyrope, $227 \mathrm{GPa}$ for zircon and $444 \mathrm{GPa}$ for diamond (e.g. Ref. [40]). Increasing the bulk modulus of the host phase should increase the 'pressure vessel' effect, and following the model of Perrillat et al. [4] the coesite inclusion will consequently reach the coesite-quartz equilibrium at lower temperatures. The amount of quartz retrogressed will thus be reduced.

Coesite inclusions with overpressure occur within both coesite-bearing Kulet and diamond-bearing Kumdy-Kol blocks of Kokchetav Massif. The composition of garnet from Kulet whiteschists are spessartine-almandine rich with minor amounts of grossular and pyrope [6,41], whereas garnet from BarchiKol are grossular-rich and have relatively high pyrope content [28]. The differences in garnet compositions should be reflected in their rheological properties, which on their turn should be reflected on the different extent of coesite to quartz transformation, which is not the case in our study. Rheological properties of zircon and garnet are even more contrasting but the values of overpressure for coesite inclusions from the same sample remain the same. It is unlikely that there are any differences in exhumation rate for garnet and zircon from the same sample. Similar phenomena occur when we compare the overpressure for different UHP complexes to different PTt history (see Ref. [5] for results). The maximum of overpressure value remains nearly constant $2.0-2.4 \mathrm{GPa}\left(526-527 \mathrm{~cm}^{-1}\right)$, although an overpressure of $\sim 3.2 \mathrm{GPa}$ was identified for coesite inclusions in diamond [7]. This may perhaps indicate that garnet and zircon are not such good containers as claimed by Refs. [42,43]. 
Despite the number of report about new finding of coesite inclusions all over the world (see [44] and references therein) the anisotropic hallo around coesite inclusions is reported for the first time in the present work. The lack of description of such anisotropic hallo around coesite inclusions for low- and medium-temperature UHPM complexes allows us to suggest that it might be a diagnostic feature of high-temperature UHPM complexes exhumed at high exhumation rates.

Hence, the survival of coesite results from a process combining the 'pressure vessel' effect of the host mineral, the kinetics of the reaction and the conditions of subsequent fracturing. The conditions under which the host mineral fractures or starts to plastically deform need further investigation for a better understanding of the coesite preservation.

\section{Conclusions}

The high-temperature coesite inclusions in garnet can be identified by the euhedral shape, the grayish interference color and the hallo, lacking around low temperature coesite inclusions.

The presence of optically unrecognizable quartz, but identifiable by Raman spectroscopy, in this type of coesite inclusions indicates that the initial stage of transformation coesite-quartz occurs even in rocks, which underwent very fast exhumation [45].

Optically unrecognizable quartz occurs as a thin shell around coesite inclusion, confirming that nucleation of quartz begins at grain boundaries of coesite-inclusion and garnet-host.

The calibration of the Raman shift of the main bands of quartz [9] and coesite [8] allows to estimate the pressure up to 2.1 and 1.6 GPa for coesite and quartz, respectively. The highest overpressure is recorded for the unexposed coesite, but even exposed coesite does not release the stress completely (the overpressure remains as high as $0.5 \mathrm{GPa} !)$.

The highest value of overpressure for coesite (2.1-2.3 GPa) inclusions in garnet and zircon remains the same for metamorphic complexes with different PTt history, while the coesite inclusions in diamond show the highest values of up to $3.44 \mathrm{GPa}$ [7]. This fact argues that the pressure release occurs during the exhumation, and therefore garnet and zircon are not so good container as has been previously claimed [42].

\section{Acknowledgments}

We thank Dr. M.A. Ziemann for drawing our attention to the problem of Raman geobarometers. The reviews provided by two anonymous reviewers are greatly appreciated. This study was financially supported by Russian Foundation for Basic Research (04-05-64360-a), MK-5077.2006.5, Russian Science Support Foundation and the Belgian Government BOSTCA. One of us (PV) wishes to acknowledge the Research Foundation-Flanders (F.W.O.-Vlaanderen) for his post-doctoral grant and for the financial support (Grant G.0156.02).

\section{References}

[1] D.C. Smith, Nature 310 (1984) 641.
[2] C. Chopin, Contrib. Mineral. Petrol. 86 (1984) 107.

[3] J.L. Mosenfelder, S.R. Bohlen, Earth Planet. Sci. Lett. 153 (1997) 133.

[4] J.P. Perrillat, I. Daniel, J.M. Lardeux, H. Cardon, J. Petrol. 44 (2003) 773.

[5] C.D. Parkinson, I. Katayama, Geology 27 (1999) 979.

[6] C.D. Parkinson, Lithos 52 (2000) 215.

[7] N.V. Sobolev, B.A. Fursenko, S.V. Goryainov, J.F. Shu, R.J. Hemley, H.K. Mao, F.R. Boyd, P. Natl, Acad. Sci. U.S.A. 97 (2000) 11875.

[8] R.J. Hemley, in: M.H. Manghnani, Y. Syono (Eds.), High-pressure Research in Mineral Physics, Tokyo-AGU, Washington, DC, 1987, p. 347.

[9] C. Schmidt, M.A. Ziemann, Am. Mineral. 85 (2000) 1725.

[10] K. Ye, J.B. Liou, B. Cong, S. Maruyama, Am. Mineral. 86 (2001) 1151.

[11] Y. Zhang, Earth Planet. Sci. Lett. 157 (1998) 209.

[12] D. Hutsebaut, P. Vandenabeele, L. Moens, Analyst 130 (2005) 1204.

[13] S.K. Sharma, J.F. Mammone, M.F. Nicol, Nature 292 (1981) 140.

[14] H. Boyer, D.C. Smith, C. Chopin, B. Lasnier, Phys. Chem. Mineral. 12 (1985) 45.

[15] N.V. Sobolev, V.S. Shatsky, Nature 343 (1990) 742.

[16] O.M. Rozen, Y.M. Zorin, A.A. Zayachkovsky, Dokl. Akad. Nauk SSSR 203 (1972) 674 (in Russian).

[17] N.L. Dobretsov, N.V. Sobolev, V.S. Shatsky, R.G. Coleman, W.G. Ernst, Isl. Arc 4 (1995) 267.

[18] V.S. Shatsky, N.V. Sobolev, M.A. Vavilov, in: R.G. Coleman, X. Wang (Eds.), Ultrahigh Pressure Metamorphism, Cambridge University Press, Cambridge, 1995, p. 427.

[19] Y. Ogasawara, M. Ohta, K. Fukasawa, I. Katayama, S. Maruyama, Isl. Arc 9 (2000) 400.

[20] J. Hermann, D. Rubatto, A. Korsakov, V.S. Shatsky, Contrib. Mineral. Petrol. 141 (2001) 66.

[21] J. Hermann, Geology Forum (2003) e4.

[22] D. Canil, Geology 18 (1990) 1011.

[23] K. Theunissen, N.L. Dobretsov, A. Korsakov, A. Travin, V.S. Shatsky, L. Smirnova, A. Boven, Isl. Arc 9 (2000) 428.

[24] K. Theunissen, N.L. Dobretsov, V.S. Shatsky, L. Smirnova, A. Korsakov, Terra Nova 12 (2000) 181.

[25] J.C. Claoue-Long, N.V. Sobolev, V.S. Shatsky, A.V. Sobolev, Geology 19 (1991) 710.

[26] J. Hermann, D. Rubatto, A.V. Korsakov, V.S. Shatsky, Russ. Geol. Geophys. 47 (2006) 511.

[27] A.V. Korsakov, V.S. Shatsky, N.V. Sobolev, Dokl. Akad. Nauk 360 (1998) 77.

[28] A.V. Korsakov, V.S. Shatsky, N.V. Sobolev, A.A. Zayachkovsky, Eur. J. Mineral. 14 (2002) 915.

[29] A.V. Korsakov, K. Theunissen, O.A. Kozmenko, Y.I. Ovchinnikov, Russ. Geol. Geophys. 47 (2006) 497.

[30] I. Katayama, S. Maruyama, C.D. Parkinson, K. Terada, Y. Sano, Earth Planet. Sci. Lett. 188 (2001) 185.

[31] H. Massago, Isl. Arc 9 (2000) 358.

[32] A.V. Korsakov, K. Theunissen, L.V. Smirnova, Terra Nova 16 (2004) 146.

[33] Y.F. Zhu, Y. Ogasawara, Geology 30 (2002) 947.

[34] A.V. Korsakov, J. Hermann, Earth Planet. Sci. Lett. 241 (2006) 104.

[35] F. Langenhorst, J.-P. Poirier, Earth Planet. Sci. Lett. 203 (2002) 793.

[36] V.J. Tekippe, A.K. Ramdas, S. Rodriguez, Phys. Rev. B 8 (1973) 706.

[37] P.M. Mirwald, H.J. Massonne, J. Geophys. Res. 85 (1980) 6983.

[38] P. Gillet, J. Ingrin, C. Chopin, Earth Planet. Sci. Lett. 70 (1984) 426.

[39] I. Van der Molen, H.L. van Roermund, Lithos 19 (1986) 317.

[40] E. Knittle, Mineral Physics and Crystallography-Handbook of Physical Constants, American Geophysical Union, Washington, DC, 1995, pp. 98-142.

[41] N.G. Udovkina, Eclogites of the USSR, Nauka Press, Moscow, 1985.

[42] N.V. Sobolev, V.S. Shatsky, M.A. Vavilov, S.V. Goryainov, Dokl. Akad. Nauk 334 (1994) 488.

[43] I. Katayama, A.A. Zayachkovsky, S. Maruyama, Isl. Arc 9 (2000) 417.

[44] C. Chopin, Earth Planet. Sci. Lett. 212 (2003) 1.

[45] N.L. Dobretsov, M.M. Buslov, F.I. Zhimulev, A.V. Travin, A.A. Zayachkovsky, Russ. Geol. Geophys. 47 (2006) 424. 